\title{
Annuities: No longer the healthy option? The implications of segmentation
}

Received (in revised form): 30th September, 2008

\section{Mike Fuller}

is Chief Executive Officer of Just Retirement, the leading provider of enhanced annuities in the UK. From 1999 until 2003 he was Chief Executive of Britannic Retirement Solutions. Before this, Mike was Managing Director of Stalwart Assurance, then the leading UK equity release provider, where he was instrumental in Stalwart's launch in August 1995 of the UK's first enhanced annuity, a 'smoker's annuity'. Stalwart's product range was subsequently extended to include annuities for those with lifestyle and critical illness factors, before Stalwart was sold to GE Capital by its private equity owners, subsequently changing its name to GE Life. Mike has over 40 years' experience in the UK life assurance industry, is a fellow of the Institute of Actuaries and an FSA Approved Person.

\begin{abstract}
Mike Fuller of Just Retirement argues that, despite increased flexibility available to retirees, annuities still offer good value for money for most people in the UK, provided that simple steps are taken to obtain the most appropriate rate and that full account of health is taken at retirement.
\end{abstract} Pensions (2008) 13, 201-206. doi:10.1057/pm.2008.29

Keywords: individual retirement funds, security and value, risk of alternatives, essential provider information, full value still not achieved

\section{Introduction}

The market for retirement income in the UK currently stands at $£ 14$ bn premium per year (ABI data 2007), of which $£ 11$ bn is accounted for by annuities, predominantly conventional annuities. According to a recent survey by Watson Wyatt, the value of the retirement income market is forecast to rise to over $\mathcal{E} 30 \mathrm{bn}$ by 2012 and to

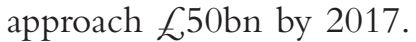

With changes in legislation ushering in more flexible investment-based income products, it is often suggested that the future of annuities is one of decline as people seek to take greater control of their retirement.

Despite the title, however, this paper is not suggesting that the 'end is nigh' for annuities. On the contrary, it is easily argued that the role of and value from annuities is much greater than many commentators give credit for.

Correspondence: Mike Fuller, Just Retirement Limited, Vale House, Roebuck Close, Bancroft Road, Reigate, Surrey RH2 7RU, UK. Tel: +44 1737233027

E-mail: mike.fuller@justretirement.com
Over the last few months, the industry has been in the midst of a large-scale review of the Open Market Option (OMO) and has been applying the principles of Treating Customers Fairly to the process of buying an annuity at retirement. The resulting improvement in communication and practices should help enhance the retirement of a great many people.

The benefit of shopping around, or taking the $\mathrm{OMO}$, for the end customer is quite clear. In June this year, the annuity being quoted by a major international insurer for a male aged 65 with a $£ 40,000$ purchase price was $£ 2,570$ p.a. Even for a healthy life, it would have been possible to increase the annuity by more than 20 per cent by going to one of the best companies. This would have produced increased payments over ten years of over $f, 5,000$ - over the 20 years more typical of life expectancy at this age, that figure would have risen to more than $\mathcal{E} 10,000$ - or 25 per cent of the original fund.

For the 40 per cent of retirees who could qualify for enhanced terms, because of lifestyle or medical factors, the uplift in benefits could, 
Table 1: Annual annuity income for a lump sum investment of $£ 50,000$

\begin{tabular}{llc}
\hline & $\begin{array}{l}\text { Annual annuity income for a lump sum investment of } \\
£ 50,000\end{array}$ & Female aged 60 \\
\cline { 3 - 3 } & Male aged 65 & \\
\hline Enhanced annuity provider (Just Retirement) & & $£ 3,847(+16 \%)$ \\
$\quad$ Severe enhancement & $£ 4,878(+27 \%)$ & $£ 3,666(+10 \%)$ \\
Material enhancement & $£ 4,553(+18 \%)$ & $£ 3,525(+6 \%)$ \\
Modest enhancement & $£ 4,392(+14 \%)$ & $£ 3,337$ \\
Standard annuity providers & & $£ 3,307$ \\
$\quad$ Aegon & $£ 3,881$ & $£ 3,318$ \\
$\quad$ Prudential & $£ 3,861$ & $£ 3,839$ \\
$\quad$ Canada life & & \\
\hline
\end{tabular}

however, be double or even possibly treble that level. Another $£ 950$ p.a. could be available even for an individual without major impairment. All that is required to achieve this is knowing where to go for the right advice and a few minutes of extra time in providing the required medical information.

And just to show that investigating enhancements can still be worthwhile against even the best offices, here is a comparison for a $£ 50,000$ case for a male of 65 or a female aged 60 (Table 1).

The main point to be made here, and one that has been made to the DWP and Treasury as part of their review of the OMO, is that clients would not willingly walk away from the extra money they could so easily enjoy ... and it would not be difficult to make internet facilities available to the end consumer to help in the information process.

This benefit does not necessarily have to be expressed simply as an increase in the pension received by the individual. In any one case there may be a number of other concerns. Just to give food for thought, consider a 67-year old who would qualify for a modest enhancement to their annuity. With a standard rate from a well-known provider, they may have received a level income of $\mathcal{E}^{3,417}$ p.a. From an enhanced annuity, the same 67-year old could receive one of the benefits shown in Table 2 .

Thus, taking advice can achieve a range of possible outcomes for the individual at, effectively, no cost to them, with either a 'free' spouse's pension, escalation or money back on death,
Table 2: Alternative benefits and income available from lump sum investment of $£ 40,000$

\begin{tabular}{|c|c|c|}
\hline Benefit & Income & Improvement \\
\hline $\begin{array}{l}\text { An enhanced } \\
\text { annuity }\end{array}$ & $£ 4,684$ & $37 \%$ more income for life \\
\hline $\begin{array}{l}\text { An annuity with a } \\
75 \% \text { spouse's } \\
\text { pension to a } \\
\text { healthy } 62 \text {-year- } \\
\text { old wife }\end{array}$ & $£ 3,743$ & $\begin{array}{l}10 \% \text { more income for } \\
\text { his life and significantly } \\
\text { more security for his wife }\end{array}$ \\
\hline $\begin{array}{l}\text { A single life } \\
\text { annuity } \\
\text { increasing at } \\
4 \% \text { yearly }\end{array}$ & $£ 3,443$ & $\begin{array}{l}1 \% \text { more in the first year } \\
43 \% \text { more in the } 10 \text { th year } \\
\text { More than twice as much } \\
\text { in the } 20 \text { th year }\end{array}$ \\
\hline $\begin{array}{l}\text { A single life } \\
\text { annuity with } \\
100 \% \text { value } \\
\text { protection }\end{array}$ & $£ 4,159$ & $\begin{array}{l}22 \% \text { more income for life } \\
\text { plus return of "unspent" } \\
\text { investment on death } \\
\text { (after tax charge of } 35 \% \text { ) }\end{array}$ \\
\hline
\end{tabular}

providing valuable protection for the retiree's or his family's future.

Therefore, how justified is the claim that four out of ten people could qualify for extra income on health grounds? Leaving aside the fact that nearly 20 per cent of retirees would do so as smokers, consider the data from the National Centre for Social Research shown in Figures $1 \mathrm{a}$ and $1 \mathrm{~b}$.

These figures are a little depressing, but they show the percentage of the population suffering from certain diseases or from obesity, according to age.

The red line in the left-hand figure indicates that for people in their 60s, approximately 30 per cent suffer from cardiovascular diseases - the blue line shows an even higher level from other chronic diseases. If there can be any good news against this background, it should be added that 

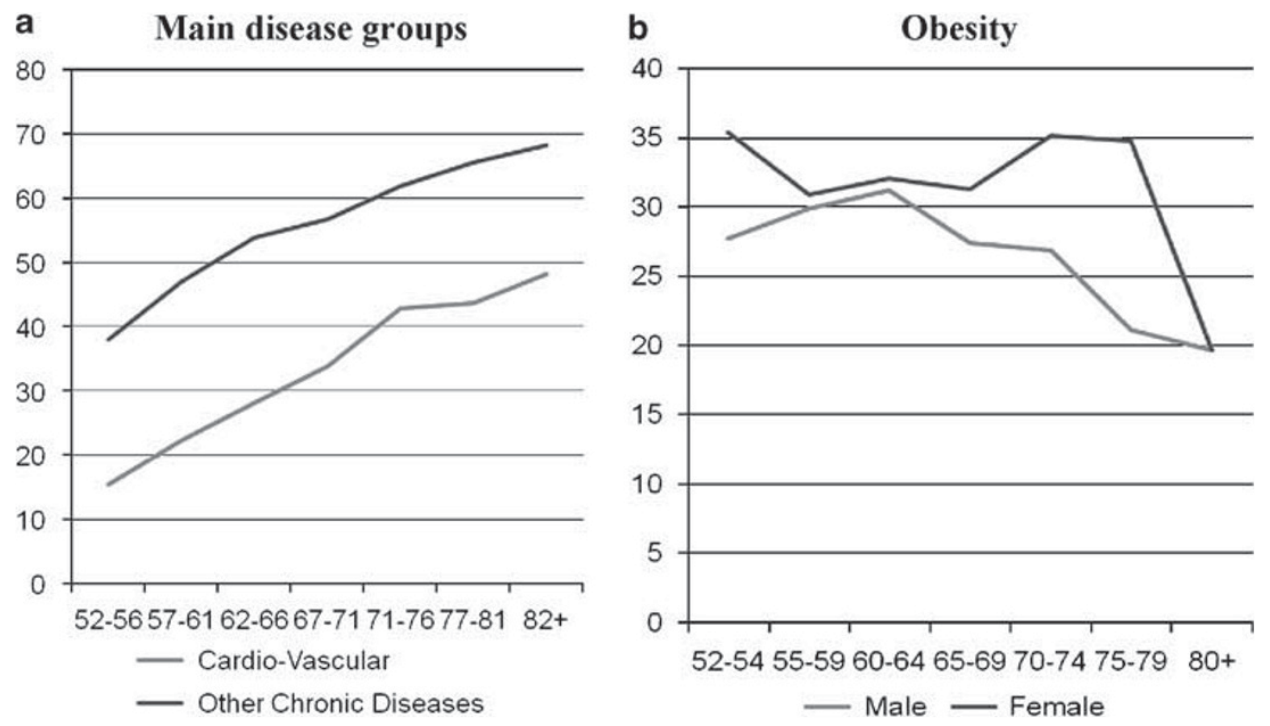

Figure 1: Prevalence of diseases and obesity (2004/05): Per cent reporting at least one disease, by age band Source: English Longitudinal Study Of Ageing: National Centre for Social Research.

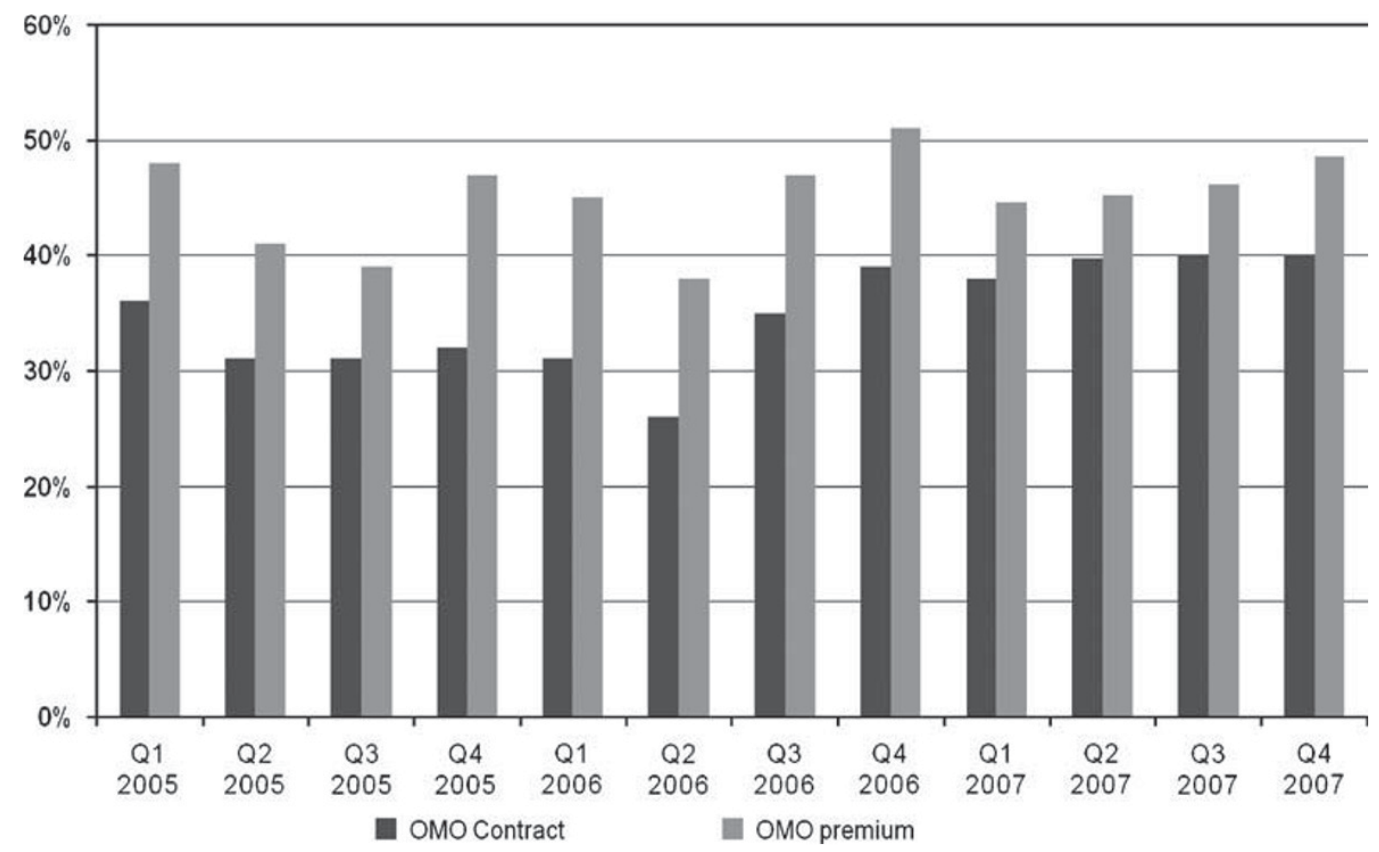

Figure 2: Use of Open Market Option: 2005-2007

so-called chronic diseases are not necessarily chronic from a life expectancy viewpoint; they just make life more unpleasant from a quality of life perspective.

Against this background one can argue that, in reality, the proportion of people who could qualify for an enhanced annuity could be even higher than 40 per cent, especially taking into account spouses with medical conditions even when the main annuitant is in good health.

Thus, it can be seen that there is considerable benefit to those with medical or lifestyle 
conditions from shopping around for the best income they can get for their circumstances. While the increases may not be so dramatic, however, there is clearly still considerable merit in those who do not qualify using the OMO to improve their income.

The other important issue affecting how well the annuity market works is how easy it is for people, whether healthy or not, to get the right advice and the benefits they deserve.

A glance at figures for take-up of the OMO (see Figure 2) shows that there has been no real increase in the premiums using this facility in three years, with the proportion generally varying between 45 and 50 per cent. There does appear to have been an increase in the proportion of contracts, or people, using the OMO, but they still only represent around 40 per cent of cases. All of this indicates that those with larger pension funds are most able, and willing, to obtain the benefit of shopping around.

From the perspective of enhanced annuities, the position is even worse:

Figure 3 shows that, despite the recent upward trend in sales, still only 10 or 11 per cent of total premiums are written as enhanced or impaired annuities.

Unfortunately, and despite the fact that this is a market expected to increase dramatically in the next five years to almost $£ 30 \mathrm{bn}, 90$ per cent of individual pension funds are currently less than $£ 50,000$ in value. It would be easy to come away with the impression that large numbers of retired individuals spend a great proportion of their time actively managing significant funds to identify growth and income-generating opportunities. In truth, however, the emphasis placed by most financial commentators on more sophisticated solutions than plain vanilla annuities is not justified by the sums generally available for investment.

As an industry, it is essential to raise the emphasis on solutions for more ordinary fund sizes - and to be clear about the true nature of retirement funds - but this requires more emphasis on the delivery of advice or at least guidance to the 90 per cent with smaller funds, rather than on product development specifically.

With the exception of some recent coverage, annuities do not often receive positive press. A narrow focus on the lack of return on early death and an only slowly awakening understanding of increasing longevity conspire to support the widely expressed view that annuities represent 'poor' value for money. Their lack of excitement and investment 'opportunity' also tends to count against them with less informed commentators.

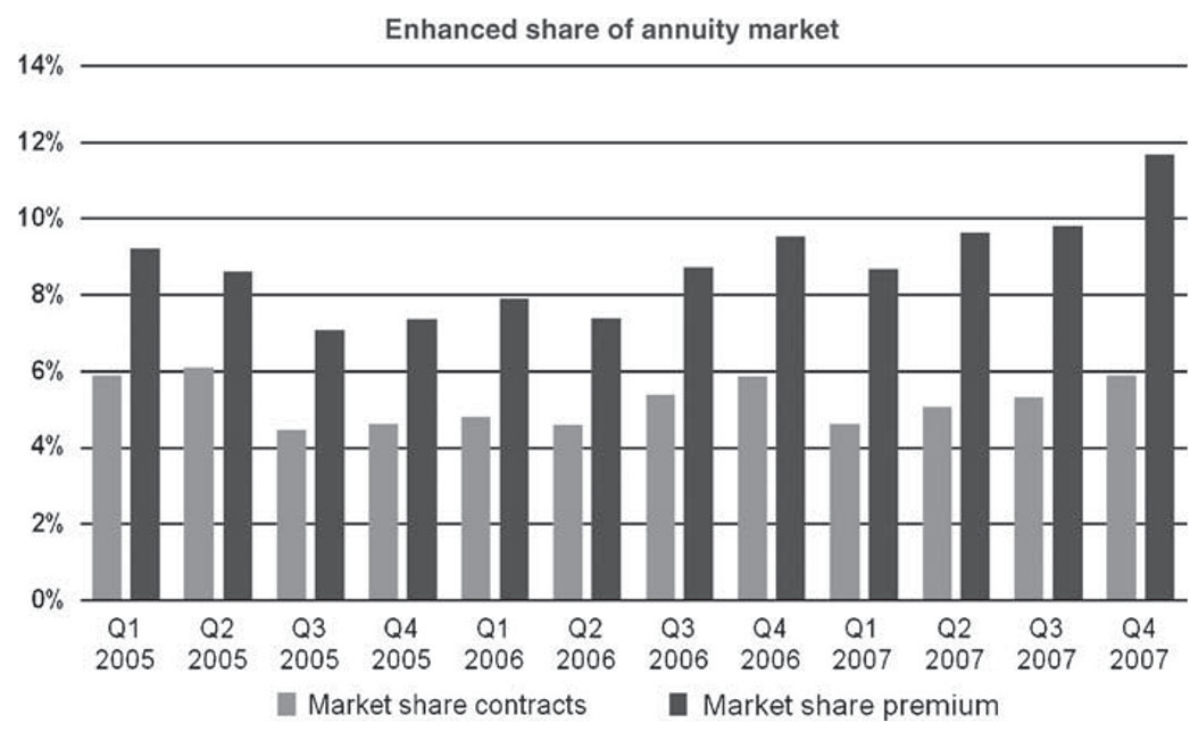

Figure 3: Use of enhanced annuities: 2005-2007 
It is important to stand firm in defence of the humble annuity contract and to explain why the secure income stream is so important, even for many of those in the top 10 per cent with the larger funds available to them.

A key measure of the effectiveness and attraction of Unsecured Pension (USP) or, for those with longer memories, income drawdown, is the return on the fund needed to sustain the income required by the individual or the income that could have been provided by an annuity, sometimes referred to as the critical yield. For a healthy 65-year old looking to match the income from the highest standard rate, the critical yield is approximately 7.5 per cent p.a. As age progresses, this will rise, gradually, to around 8 per cent p.a. at age 74 . In part, this is a reflection of the increasing mortality allowance in annuities as age increases. In today's investment environment, obtaining this rate of return with a high degree of consistency is quite a punishing target. Add in the availability of an enhancement, however, and the critical yield can easily run up to 8 per cent from 65 and to over 10 per cent by age 74 . This highlights the need for any adviser to take into account both age and health at inception and at regular reviews to ascertain whether such a product is advantageous. It also highlights the effective value of the income stream from an annuity - which is guaranteed.

Failure to maintain this rate of return will ultimately impact the income received by the individual and, due to the requirement to draw income, downside shocks can have a disproportionately large effect that may not be reversible. Thus, the individual needs to be able to survive on an income lower than that available from the annuity, possibly for a substantial period, in order to be able to sustain the risk inherent in this type of product. In general, this will limit the attraction to those with very large funds.

Recently in the UK, products have emerged offering guarantees on the income. These products are not new, being essentially amended versions of variable annuity products that have been available in other countries, notably the United States. The guarantee, however, is usually at a lower level than that offered by an annuity and results in additional charges. The additional charges effectively push up the critical yield, to around 8.5 per cent for a healthy individual and 9.5 per cent for someone with a medical condition at 65 . With these products, if the income drawn is higher than a certain level, the guarantee may be affected unless investment returns are able to redress the balance. Thus, the individual must still be able to survive on a lower level of income if circumstances demand. Again, this tends to be the preserve of those with substantial funds.

Oddly, health can also be a factor for someone contracting a medical situation during a USP investment period. In effect, deteriorating health during the investment period effectively reduces the critical yield required over the whole period. The explanation for this seemingly perverse situation is that the cost of purchasing the eventual annuity has now reduced, because such a person will obtain the benefit of enhanced annuity terms.

This is hardly a strong argument in favour of variable annuities. Clearly, variable annuities may well make sense for the better off who can accept the risks inherent in equities, but there is one other aspect in the segmentation of annuities that should be considered.

Table 3 shows the position for someone on average earnings who wishes to enjoy a total pension of two-thirds of those earnings.

The cost of buying the private pension element, over and above the basic state pension and an assumed high level of second tier pension,

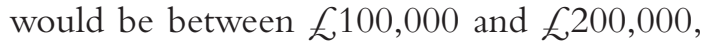
depending on the type of pension required.

Table 3: Illustration of fund requirement for average earner

\begin{tabular}{ll}
\hline Average gross earnings & $£ 26,000$ \\
Basic State Pension & $£ 4,700$ \\
Second Tier Pension (say) & $£ 5,000$ \\
Private income required & $£ 7,600$ \\
Total income & $£ 17,300$ \\
$\begin{array}{l}\text { Fund required (joint life } \\
\text { increasing) }\end{array}$ & $£ 200,000$ \\
\hline
\end{tabular}


My concern is that it often seems to be the case that funds of this size are said to be appropriate for drawdown or other equity-based arrangements. My very strong view is that someone on average earnings, or even twice that level, is almost certainly not in a strong enough financial position to be able to withstand the downside risk of poor investment performance during the early years of retirement. To a large extent, this renders the critical yield consideration irrelevant at smaller fund sizes.

Incidentally, it is also worth mentioning that this example serves to emphasise how poorly the industry has been doing, in that it puts the 90 per cent below $£ 50,000$ funds into the perspective of the size of fund at retirement really needed.

At the risk of over-simplifying matters, the less well off, those with smaller pension funds, generally have below average life expectancies. In other words, it is this very group of lives who are most likely to be in poorer health and hence more likely to qualify for enhanced annuities. Furthermore, this same group is the one least likely to know where to go for help. This view has been borne out by the recent research undertaken by the DWP in connection with attempts to improve the working of the OMO (Information needs at retirement: Qualitative research focusing on annuitisation decisions).

This is the area where more can be done. For example, the technology is now available to provide more meaningful guidance through the internet, even as far as real-time quotes.

It is also to be hoped that the Retail Distribution Review will see this as an area where the simplification of advice rules will facilitate advisers being able to provide straightforward guidance, without having to get caught up in detailed and comprehensive fact finds.

If the annuity landscape could be changed in this way, we would see more overall trust and confidence in pensions, the exit of the providers offering poor rates and more new entrants because they would be fishing in a bigger OMO pool.

But couldn't the existing standard providers then fall back on the argument that this would be bad for annuity rates generally?

As a higher proportion of those who are entitled to an enhancement actually claim it, there will be an adjustment in the level of standard, or healthy-life rates, with a reduction of only around 4 per cent if the enhanced and impaired market were to fulfil its potential of 40 per cent of the total market. In the meantime, retirees with medical conditions could receive, on average, 10 per cent more.

Another way of looking at this is to remember that annuities are life assurance against living too long. It is hard to believe that life companies are going to stop asking for medical information on ordinary life assurance - to do so would cost them a great deal of money. A cynic might argue that to start asking for similar information on annuities might also cost them a great deal of money.

Despite misconceptions and their lack of excitement, annuities have a lot to offer: lifetime security, peace-of-mind and a reasonable return in the current environment. Improving the mechanism by which those at retirement realise their income can yield improvements equivalent to an additional $f 500 \mathrm{~m}$ per year in fund values. 